\title{
ACADEMIC TOURISM \& INTERNATIONAL PEDAGOGICAL INNOVATIONS
}

\author{
Michael A. Radin \\ Olga A. Orlova
}

https://doi.org/10.20867/tosee.05.34

\begin{abstract}
The primary goal of this paper is to render academic tourism and how it welcomes and expands two directional international pedagogical innovations and prolongs the tourist season. First of all, we will portray how traveling opens doors to a new journey and to a new learning atmosphere. Second of all, we will convey how long term travels not only extend the tourism season but also unfold new horizons and incite new international innovations while participating at conferences, seminars, semester abroad programs and sabbaticals. In addition, we will describe the long-term academic tourism as a two directional learning process that we can experience; introducing and sharing new ideas with students and colleagues and developing new ideas from students' and colleagues' feedback while traveling, studying and teaching abroad. Furthermore, we will focus on how feedback during our lengthened journeys from colleagues can open advanced opportunities for new seminars, new research projects, writing new papers and textbooks and welcome us to new international and interdisciplinary teaching and learning atmosphere. Moreover, throughout our extensive travels we often encounter numerous possibilities to establish new international contacts and collaborations and gain valuable feedback that guides us to new horizons.
\end{abstract}

Keywords long-term traveling tourism season, hands-on teaching style, international learning, international teaching, feedback, pedagogical innovations, risk management

\section{INTRODUCTION}

Lengthy travels and tourist seasons can be viewed as journeys that guide us to new horizons of learning experiences and innovations. We define an innovation as an introduction to something new and has been a vital method in solving problems and steering to further improvements, especially during the $20^{\text {th }}$ century. New technological innovations can be discovered during extended journeys and are vital for more efficient international communications and traveling. In addition, while teaching abroad in a different environment we can perceive that pedagogical innovations are essential as students' learning styles change from generation to generation and due to educational reforms, cultural changes and international globalization influences (Orlova \& Radin, 2018). Extended international travels broaden our global perspectives and help us stay abreast of these changes, adjust to these changes and provide students with contemporary information literacy, pedagogical literacy, organizational literacy and temporal literacy (Briere, Macsuga \& Simonsen, 2012). In addition, extended international travels can promote new collaborations and hence influence new teaching styles and innovations (Radin \& Riashschenko, 2017). 
ToSEE - Tourism in Southern and Eastern Europe, Vol. 5, pp. 597-605, 2019

M. A. Radin, O. A. Orlova: ACADEMIC TOURISM \& INTERNATIONAL PEDAGOGICAL

Our primary goal of this paper is to convey how various innovations can often emerge during long term international journeys and how traveling can be a valuable learning experience that directs us to innovations and leadership together with feedback. For instance, after traveling in China, Marco Polo introduced gun powder and pasta to Europe that instantly ignited many technological and culinary innovations and changes throughout Europe. In addition, while living in Zaandam, Netherlands, Peter the Great of Russia learned to build ships and very shortly established the Russian Navy. What ideas can we introduce to students and colleagues during our long term traveling experiences and while studying and teaching abroad? What new ideas can we gain from students' and colleagues' feedback? Throughout this paper we will portray how we gain feedback as a vital tool in developing successful and effective international and interdisciplinary pedagogical innovations while traveling extensively that stimulate an active and amiable learning atmosphere (Kennedy \& McGarthy, 2013).

This leads to other vital questions such as why feedback is important and how to interpret feedback correctly (Hussain \& Khan, 2016)? What impacts and differences do new ideas and innovations produce and how do students and participants benefit from them? What are the potential risks and problems that can occur and how to manage and minimize them? Who are our competitors and how do we benefit from them (Radomska, 2014)? Feedback and other such factors are pertinent to obtain during lengthy journeys that will expand our new horizons of international experiences and innovations.

Our further aims of this paper are to coalesce feedback, innovations and successful international teaching and learning practices during extended journeys. Combining them together to advance with future pedagogical ideas such as hands-on teaching styles, new seminars and topics for conference presentations and new ideas for research papers and books. In addition, we will emphasize how flexibility with students' and colleagues' feedback can often become a vital tool in designing and implementing these new pilots that direct us to pedagogical innovations (Corley, 2010). We will apply the data and experiences during the last 15 years by using students' feedback and feedback from colleagues while teaching courses, conducting seminars and delivering presentations and workshops at conferences during international elongated journeys. We will especially emphasize how the students' and colleagues' feedback stimulated innovations by applying the student evaluations from Riga Technical University, Transportation and Sakaru Institute and Liepaja University, and the participants' feedback from the Canadian Mathematical Society annual conferences, American Mathematical Society annual conferences and other international and interdisciplinary annual conferences.

\section{WHY STUDY AND TEACH ABROAD?}

In this section we will portray how we can expand our learning horizons during our elongated traveling seasons; either while studying or teaching. We define long-term traveling as a discovery journey together with new learning experiences and innovations. For instance, as we are discovering a new city, it would be worthwhile to detect the contrasts with known cities (comparing St. Petersburg and Venice). In addition, while we are on a new alpine journey, it is interesting to find the disparities with a familiar 
ToSEE - Tourism in Southern and Eastern Europe, Vol. 5, pp. 597-605, 2019

M. A. Radin, O. A. Orlova: ACADEMIC TOURISM \& INTERNATIONAL PEDAGOGICAL ...

mountainous system (comparing the Rocky Mountains and the Alps). Extended tourist season boosts these unique and compelling learning experiences.

We will commence with our first question: why study or teach overseas during our lengthy trips? First of all, it is an interesting and a challenging prolonged educational journey that offers cross-cultural comparisons between cultures and educational systems; collating our native culture and educational system together with the new culture and educational system. What successful ideas and practices we can share and what schemes and customs can we adapt during our elongated journeys? Second of all, to expand and strengthen our horizons it is beneficial to analyse and understand the differences between teaching and learning styles and other analogous cultural differences that can arise during our extended stay. It is especially essential to understand the students' preparation level prior to implementing new ideas or innovations to minimize the risk of problems and failures (Radomska, 2014). We will discuss how to minimize these risks in the later section of the paper with the following questions. What potential cultural barriers can emerge during our extended travels and how do we cross the cultural barriers in order to successfully implement our pedagogical innovations? What new ideas and innovations can arise during our extended cultural and academic journeys? We will share about successful international traveling experiences to remit these questions.

For instance, Michael decided to pioneer his hands-on teaching style while taching various courses in different universities in Latvia during his spring 2016 semester sabbatical. This style includes hands-on practice problems during class, active class participation with questions, and active discussions of homework assignments during class and office hours. He successfully implemented this teaching style in his classes that he teaches regularly at RIT and received perpetual positive and supportive teaching evaluations from his students. Michael then decided to implement this hands-on teaching style with his students while teaching Introduction to Discrete Mathematics for Scientists and Engineers at TSI (Transportation and Sakaru Institute) in Riga, Latvia and encountered a few challenges. First of all, as the students were given hands-on practice problems to solve in class they asked "How are we supposed to solve the problem when you have not taught us anything yet?" Michael then responded to students' concerns: "You do not learn by watching others and you learn better by trying to solve problems on your own first". It took the students about two weeks to get acclimated to this new hands-on teaching and learning style. The students also welcomed this teaching and learning style and actively participated in class by suggesting more efficient solutions to several problems. In addition, students came regularly to office hours and asked questions on the homework assignments and understood that learning also occurs outside the classroom too. Students wrote very positive and supportive teaching evaluations and TSI rector Igors Graurs told Michael "These are the best and the highest students' evaluations that I have seen in 10 years". 
ToSEE - Tourism in Southern and Eastern Europe, Vol. 5, pp. 597-605, 2019

M. A. Radin, O. A. Orlova: ACADEMIC TOURISM \& INTERNATIONAL PEDAGOGICAL ...

Table 1: Student evaluations at TSI during the spring 2016 semester.

\begin{tabular}{|c|c|c|c|c|c|c|c|c|}
\hline $\begin{array}{l}\text { Teacher } \\
\text { / Subject }\end{array}$ & 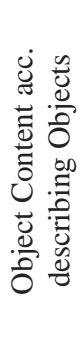 & 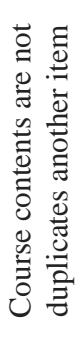 & 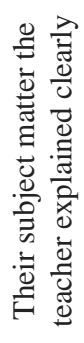 & 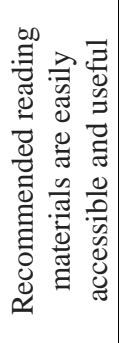 & 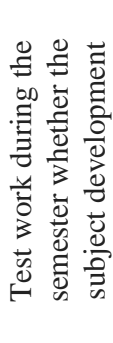 & 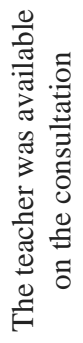 & 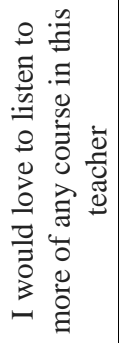 & 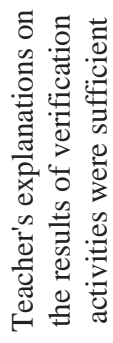 \\
\hline $\begin{array}{l}\text { Michael } \\
\text { Radin }\end{array}$ & 4.91 & 4.91 & 5.00 & 4.55 & 4.91 & 4.80 & 4.91 & 4.82 \\
\hline $\begin{array}{l}\text { Discrete } \\
\text { Mathe- } \\
\text { matics }\end{array}$ & 4.91 & 4.91 & 5.00 & 4.55 & 4.91 & 4.80 & 4.91 & 4.82 \\
\hline
\end{tabular}

Observe that the averages in the above table are out of 5. In fact, $98 \%$ of the students expressed interest in taking a different course with Michael sometime in the future.

Furthermore, during his spring 2016 sabbatical Michael taught Introduction to Photography at Liepaja University. Michael was asked to teach this basic introductory course by the Director or Liepaja University Art School during her visit to RIT prior to his sabbatical. This was also a hands-on course that required students to take photographs on a daily basis, present them at the beginning of each class and the rest of the students in the class we required to provide constructive criticisms of each photograph (indicating mistakes and problems and offering suggestions how to improve the photograph). This guided students to discovering the principles of photographic composition and enhanced their communication skills. At first students were shocked with this teaching style and reacted: "How can we take photographs if you have not taught us anything yet?" Michael then responded: "You need to take several photographs and interpret light on your own first". Students' enthusiasm gradually blossomed throughout the semester and showed pride in their photographs during each presentation and ardently participated in discussions with their comments. This was a vital learning experience for Michael as this was the first time he taught such a course with leading and moderating discussions, especially with foreign students.

In addition to teaching semester long courses at TSI and Liepaja University, Michael conducted a two day hands-on seminar on "Establishing and Developing International and Interdisciplinary Research Coalitions" supported by Riga Technical University Doctorate School. The first part of the seminar addressed how to start establishing international and interdisciplinary research coalitions by using available resources and the second part remitted how to implement ideas. The seminar's goals is to provide specific examples how successful coalitions were developed and implemented, what common ideas can be applied in various circumstances or various combinations of disciplines, and how to establish successful coalitions within limited resources and constraints. Michael received very supportive and positive evaluations; $84 \%$ of the students thought the seminar was very interesting, engaging and certainly beneficial as 
ToSEE - Tourism in Southern and Eastern Europe, Vol. 5, pp. 597-605, 2019

M. A. Radin, O. A. Orlova: ACADEMIC TOURISM \& INTERNATIONAL PEDAGOGICAL ...

well. The graph below shows students' satisfaction averaging 4.22 out of $5 ; 84 \%$ satisfaction.

Figure 1: Student evaluations at Riga Technical University; June 2017.

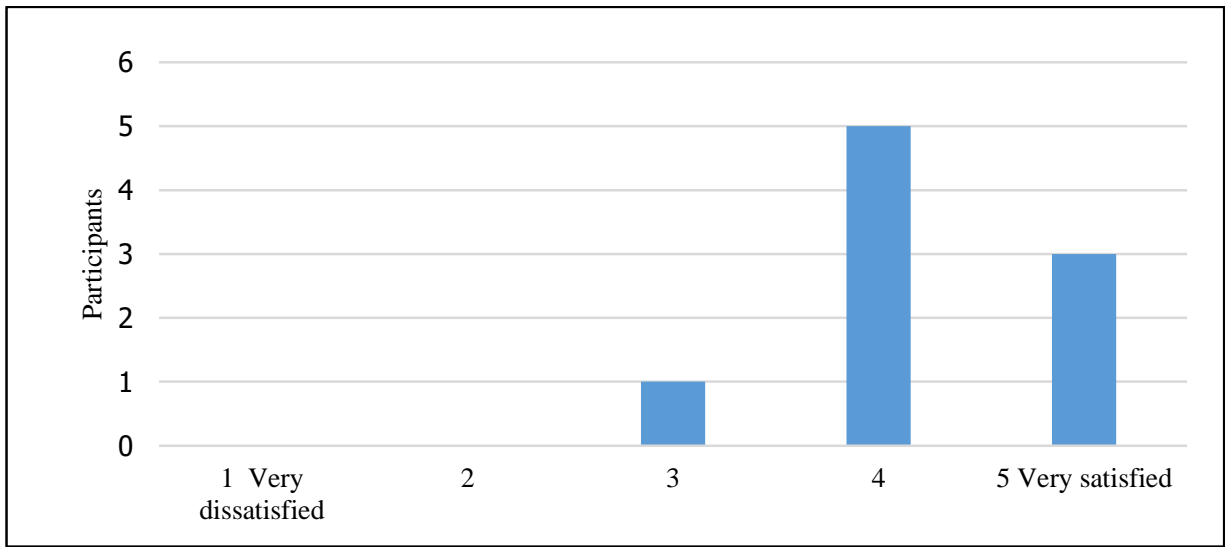

Olga Orlova is currently a mathematics Ph.D. student at Munich Technical University and also experienced elongated academic journeys as a student. Prior to studying at Munich Technical University, Olga studied at Tallinn Technical University in Estonia. Olga explored the American educational system while studying at the University of New Mexico during her spring 2016 semester. She got acquainted with the American handson teaching and learning style and with the voluminous quantity of homework assignments in all her courses during her studies at the University of New Mexico. This was quite a culture shock to Olga as she never experienced such large quantity of homework assignments in any of her courses at Tallinn Technical University. She then began to understand the American principal that at least $80 \%$ of the learning occurs outside the classroom (Waite, 2011). This was a very beneficial international learning experience for her; additional hands-on education outside the classroom helped her understand the fundamental differences in teaching and learning styles that can occur in different educational systems and how acclimation is a pertinent tool for success (Hake, 1998; Smallbone \& Quinton, 2010).

This valuable experience helped Olga to acquire a position as a doctoral student at Munich Technical University which ranks as the first place in Germany and is among Top 100 universities worldwide according to QS World University Rankings. In addition, Olga gained substantial respect by her former professors and colleagues in Estonia after her experiences with international education and conducting research in a competitive team at Munich Technical University. In fact, she was invited to be the part of the organizers' team of the International Conference on Sampling Theory and Applications which took place in Tallinn, Estonia, in 2017. Furthermore, she was twice invited to present a talk at Estonian Days of Mathematics, a biannual event sponsored by the Estonian Mathematical society. Moreover, she was invited to give a lecture to firstyear mathematics students at Tartu University and to give a talk at workshop "Mathematics and Imagination" which is a part of Estonian Annual Philosophy Conference. 
ToSEE - Tourism in Southern and Eastern Europe, Vol. 5, pp. 597-605, 2019

M. A. Radin, O. A. Orlova: ACADEMIC TOURISM \& INTERNATIONAL PEDAGOGICAL ...

\section{PROBLEMS AND POTENTIAL RISKS}

Academic tourism certainly welcomes new opportunities for students and professors with new teaching and learning experiences and welcomes new innovations and collaborations. However, there are always associated risks of problems and failures that can occur during implementation of new innovations inside and outside the classroom and while establishing international collaborations. We will commence with addressing the vital question: Why there is a risk and what possible problems can arise (Brent \& Felder, 1996)? First of all, anytime an idea or innovation is performed, there is never $100 \%$ guarantee that it will be successful (Radomska, 2014). In fact, problems always arise during each implementation. Second of all, problems can occur due to different students' preparation levels, due to students' different learning styles (Jerkins, 1991), and due to cultural differences (Radin \& Riashchenko, 2017). For instance, a specific pedagogical innovation can be successful in one academic system and yet experience challenges and possible failures in a different environment. We shared about these experiences and challenges in the previous sections. It is essential to be flexible to feedback and new ideas during implementation and will be one of the methods to reduce the risk of emerging problems and failures. Using the diagram below, we will address how do to apply feedback in order to manage and minimize these potential risks.

Figure 2: Risk Management Diagram.

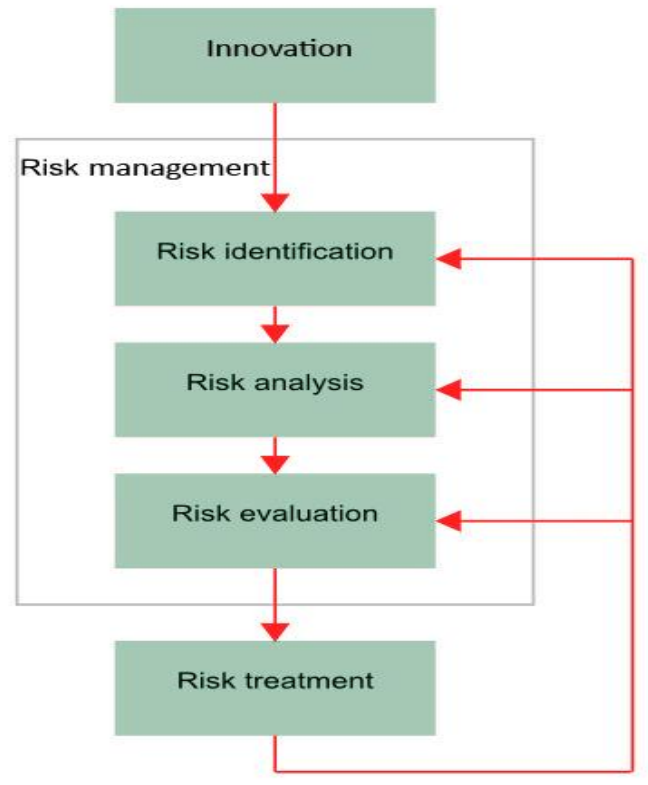


ToSEE - Tourism in Southern and Eastern Europe, Vol. 5, pp. 597-605, 2019

M. A. Radin, O. A. Orlova: ACADEMIC TOURISM \& INTERNATIONAL PEDAGOGICAL

While applying Risk Management, the first vital step in minimizing the risk is to identify the potential problems that can occur using the students' and colleagues' feedback and using the supervisors' feedback (Radomska, 2014; Rosenfeld 2008). For instance, before conducting his seminar on "Developing and Establishing Successful International and Interdisciplinary Research Coalitions" at Riga Technical University, Michael consulted with the head of Doctoral School and gained valuable feedback and advices and hence acquired very beneficial ideas and thus guided him in the right direction with several revisions before coordinating the seminar. This was the first time that Michael conducted such a seminar and certainly was not yet familiar with the diverse academic graduate student atmosphere at Riga Technical University. In addition, before conducting his Risk Management Seminar at Riga Technical University Department of Engineering Economics, Michael had numerous discussions with his supervisor who steered him in the right direction with the appropriate topics and structure that were essential for the seminar. Both of these discussions served as a vital tool for minimizing the risk of failures or problems as Michael got acquainted with Riga Technical University's guidelines and objectives and helped Michael obtain positive and supportive evaluations. Michael will continue to conduct these seminars annually at Riga Technical University.

The second pertinent step in applying Risk Management is to thoroughly analyse the risk factors that may occur beyond our control and to develop strategies how to handle them properly. Using students' and colleagues' feedback after implementing the innovation is just as vital as feedback prior to implementation (Shuell, 1986; Smallbone \& Quinton, 2010). Analysing the feedback and incorporating changes after the feedback are essential for future improvements before implementing the innovation the second time around. Furthermore, while implementing a certain innovation each time, it is important to gauge the students' learning styles and the overall learning atmosphere and make the necessary changes to pioneer the innovation in the right direction (Orlova \& Radin, 2018). The final step of applying Risk Management is to evaluate and assess the entire process and make conclusions by addressing the following questions: What are the advantages and disadvantages of the new innovation? For what reasons did problems or failures occur? Are these minor problems or very serious problems? How likely are they to repeat? Shall we proceed with improvements or try a different innovation instead? That again will depend on the feedback. Do negative repetitive comments appear repeatedly each time?

\section{CONCLUSIONS AND FUTURE INNOVATIONS}

We shared about several successful international teaching and learning experiences during lengthy journeys that trained us to be flexible and open to feedback and new ideas that can welcome new horizons. However, these rendered only the first phase of academic tourism explorations and certainly pose new questions to contemplate about. First of all, what are the primary and most noticeable differences between the educational systems and teaching and learning styles we can detect during our lengthy international journeys? Second of all, how do we decipher feedback and constructive critiques for further improvements and new innovations? Also how do we transform others' ideas and then pioneer our own innovations? In addition, what additional thoughts and tools will be required to implement colleagues' feedback and suggestions? Feedbacks and suggestions do not portray all the necessary details and only guide us to new horizons 
ToSEE - Tourism in Southern and Eastern Europe, Vol. 5, pp. 597-605, 2019

M. A. Radin, O. A. Orlova: ACADEMIC TOURISM \& INTERNATIONAL PEDAGOGICAL ...

instead. If a colleague suggests to write a book or a textbook, how do we choose a new topic that does not conflict with any of the current books? For instance, when Michael was invited to write a textbook by Springer, he chose "Periodic Character and Patterns of Recursive Sequences" as a new topic compared to other textbooks. In addition, when Michael was invited to write a textbook by World Scientific Publishing Company, he selected "Difference Equations for Scientists and Engineers" as a new topic relative to the existing textbooks. Understanding and implementing reviewers' and publishers' feedback was pertinent as a notice writer and yet it was just as vital to stay innovative with new ideas while writing both textbooks in inductive style by providing several repetitive-type examples that lead to development of theorems. This has been Michael's successful teaching practice during the last 10 years and Rochelle Kronzek (World Scientific Publishing Company) suggested Michael to include this successful classroom practice in the textbook's introduction. Moreover, Michael will be conducting a special workshop on "Balance Between Leading and Following and Successful International Pedagogical Innovations" at the Society, Integration, Education International Scientific Conference in May 2019.

\section{REFERENCES}

Bielaczyk, K., Collins, A., Joseph, D. (2004), "Design research: Theoretical and methodological issues", Journal of the Learning Sciences, 13(1), pp. 15-42.

Brent, R., Felder, R.M. (1996), "Navigating the bumpy road to student - centered instruction", College Teaching, 44(2), pp. 43-47.

Briere, D.E., Macsuga Gage A.S., Simonsen B. (2012); "Effective teaching practices that promote a positive class environment", Beyond Behavior, 22(1), pp. 14-22.

Brooks,J.S., Normore, A.H. (2010), "Educational Leadership and Globalization: Literact for a Glocal Perspective", Sage:Educational Policy, 24(1), pp. 52-82.

Cook, L., Friend, M. (1995), "Co-teaching: Guidelines for creating effective practices", Focus on Exceptional Children, 28(3), pp. 1-17.

Corley, T. (2010), Rich Habits: The Key to Success and a Happy Future, Langdon Street Press, ISBN 13: 978 1-934938-93-5.

Grasha, A.F., Yangarber-Hicks, N. (2000), "Integrating teaching styles and learning styles with Instructional Technology", College Teaching, 8(1), pp. 2-11.

Graziano, K.J., Navarrete, L.A. (2012), "Co-teaching in a teacher education classroom: Collaboration, compromise and creativity", Issues in Teacher Education, 21(1), pp. 109-124.

Herman, R.L. (2011), "What Makes an Excellend Professor?” TheJournal of Effective Teaching, 11(1), pp. 1-

Huberman, M. (1983), "The role of teacher education in the improvement of educational practice: A linkage model", European Journal of Teacher Education, 6(1), pp. 17-29.

Hussain, M., Khan, S. (2016), "Students' feedback: An effective tool in teachers' evaluation system", International Journal of Applied Basic Medical Research, 6(3), pp. 178-181.

Kennedy, D., McGarthy, D. (2013), "Feedback in the Academic and Industrial Environment", INTED 2013 Valencia, Spain, pp. 4-6.

Khnyfr, H. (2005), "The higher education system in the world with strategy", Journal of Cultural Management, $3(9), 10$.

MacMillan, R.B. (2000), "Leadership succession: Cultures of teaching and educational change”, In N. Bascia and A. Hargreaves, The Sharp Edge of Educational Change: Teacing, leading and realities of reform, New York: Routledge/Falmer, pp. 52-71.

Matthew, D.B. (1996), "An investigation of learning styles and perceived academic achievement for high school students", Clearing House, 69(4), pp. 249-255.

Murgulis, E. (2012), "Music repetition detection acrss mulitple exposures", Music Perception, 29, pp. 377 385.

Orlova, O., Radin, M. (2018), "Re-photographing the Baltic Sea Scenery in Liepaja: Why Photograph the same scenery multiple times?” Scriptus Manet: Journal of Humanities and Arts 2018, 1(7), pp. 71-84 
ToSEE - Tourism in Southern and Eastern Europe, Vol. 5, pp. 597-605, 2019

M. A. Radin, O. A. Orlova: ACADEMIC TOURISM \& INTERNATIONAL PEDAGOGICAL

Orlova, O., Radin, M. (2018), "University level teaching styles with high school students and international teaching and learning", The proceedings of the International Scientific Conference "Sociaty, Integraton, Education", Vol. 1, pp. 464-475.

Radin, M., Riashschenko, V. (2017), "Effective pedagogical management as a road to successful international teaching and learning", Forum Scientiae Oeconomia, 5(4), pp. 71-84.

Radomska, J. (2014), “Operational Risk associated with the Strategy Implementation”, De Gruyter, 18(2), pp. 31-43.

Rosenfeld, M., Rosenfeld, S. (2008), "Developing effective teacher beliefs about learners: The role of sensitizing teachers to individual differences", Educational Psychology, 28(3), pp. 245-272.

Shields, P.M. (2003), “A pragmatic teaching philosophy”, Journal of Public Affairs Education, 9(1), pp. 7-12

Smallbone, T., Quinton, S. (2010), "Feeding forward: Using feedback to promote student reflection and learning-a teaching model", Journal of Innovations in Education and Teaching International, 47(1), pp. 125-135.

Spendlove, M. (2007), "Competencies for effective leadership in higher education", International Journal of Educational Management, 21(5), pp. 407-417.

Tomlinson, C.A. (2005), "Quality curriculum and instruction for highly able students", Theory Into Practice, 44(2), pp. 160-166.

Vermunt, J.D. (1998), "The regulation of constructive learning process", British Journal of Educational Psychology, 68, pp. 149-171.

Waite, S. (2011), "Teaching and learning outside the classroom: personal values, alternative pedagogies and standards", Education 3-13. 39(1), pp. 65-82.

Wiggins, G. (2012), "Seven Keys to Effective Feedback”, Educational Leadership, 70(1), pp. 10-16.

Michael A. Radin, PhD, Associate Professor of Mathematics

Rochester Institute of Technology

School of Mathematical Sciences

Rochester, New York 14623 U.S.A.

E-mail: michael.radin@rit.edu

Olga A. Orlova, Doctorate Student

Munich Technical University

Department of Mathematics

Munich, Germany

E-mail: olga.a.orlova@gmail.com 